\title{
GESTÃO DE TECNOLOGIA DE INFORMAÇÃO: UM MÉTODO DE AVALIAÇÃO DO WMS
}

\author{
INFORMATION TECHNOLOGY MANAGEMENT: \\ A METHOD FOR ASSESSING WMS
}

\author{
(artigo submetido em fevereiro de 2012) \\ Priscilla Cristina Cabral Ribeiro \\ Doutora em Engenharia de Produção pela \\ UFSCar e Professora do Depto. de \\ Engenharia de Produção da Universidade \\ Federal Fluminense \\ priscillaribeirodid.uff.br \\ Nayara Louise Alves de Carvalho \\ Engenheira de Produção pela Universidade \\ Federal de Ouro Preto (UFOP) \\ nayaralouiseopeyahoo.com.br
}

\begin{abstract}
The Warehouse Management System is an Information Technology (TI) which helps companies in their warehouse operations and inventory, giving a more appropriate use to the space of distribution centers (DCS). Even though the operational and financial results of the implementation of IT, such as the WMS, are positive and clear, results related to safety and other technical issues need to be assessed more accurately, considering that IT demands high investments. Thus, to evaluate the WMS, this paper presents a literature review on technologies, IT, IS, and WMS, and then applies the method of Ribeiro and Carvalho to companies that offer logistics services such as Logistics Operators. A case study method will be used for that, following a qualitative approach based on semistructured interviews with Logistics Operators. Among the results, it was found that these companies still give greater emphasis to the economic analysis of IT and must therefore improve the assessment of new software by involving variables that account for organizational, safety and other technical issues, in addition to the financial variables currently in use.
\end{abstract}

Key-words: assessment; information technology; logistic; logistics operators; warehouse management system.

\begin{abstract}
RESUMO
O Warehouse Management System é uma ferramenta de Tecnologia de Informação (TI) que tem auxiliado as empresas em suas operações de armazenagem e estoque, fazendo com que o espaço dos centros de distribuição (CDs) tenha um uso mais apropriado. Embora os resultados operacionais e econômicos da implantação de sistemas como o WMS sejam positivos e claros, os ligados à segurança da informação e outros aspectos técnicos precisam ser avaliados com maior rigor, pois os investimentos são elevados. Assim, esse artigo tem como objetivo apresentar o método de Ribeiro e Carvalho, aplicando-o a empresas que ofertam serviços logísticos, como os Operadores Logísticos (OLs). Foi utilizado o método de estudo de caso, com uma abordagem qualitativa, com entrevistas semiestruturadas em OLs. A partir dessa pesquisa, verificou-se que essas empresas ainda concedem maior ênfase à análise econômica da TI e se beneficiariam da ampliação do escopo de avaliação de software novo por meio da inclusão de variáveis que capturassem benefícios organizacionais, de segurança e técnicas (além dos econômicos).
\end{abstract}

Palavras-chave: avaliação; logística; operadores logísticos; sistema de gerenciamento de armazéns; tecnologia de informação. 


\section{INTRODUÇÃO}

As organizações têm se preocupado, além dos seus custos, com aspectos como diferenciação de produtos e serviços, tecnologia da informação (TI), inovação e cadeia de suprimentos (CARVALHO, 2012). Pela amplitude de sua atuação, a logística tem sido considerada como uma das principais estratégias do negócio. Segundo Ribeiro, Meyer e Freitas (2012), as empresas têm se deparado com a seguinte decisão: terceirizar ou não as atividades logísticas. Pela dificuldade de gerenciar as atividades logísticas e por decidir focar nas atividades essenciais para a produção, muitas empresas optam por terceirizar as atividades logísticas e contratam os serviços dos operadores logísticos (OLs) para realizar a entrega de seus produtos ao cliente. Para executar essas atividades de forma eficiente, desde o ponto de origem (embarcador-fornecedor dos produtos) até o destino (cliente varejista), os OLs usam a TI que permite um melhor planejamento e gerenciamento do fluxo logístico, garantindo a entrega de produtos no prazo, nas quantidades e condições desejadas, um conjunto dos principais indicadores de satisfação dos clientes.

No que tange à atividade de armazenagem (incluída entre as atividades logísticas), no caso específico dos depósitos, armazéns e grandes centros de distribuição (CDs), o sistema de gerenciamento de armazém (Warehouse Management System - WMS) pode ser considerado uma alternativa de $\mathrm{Tl}$ adequada para otimizar a atividade de armazenagem, já que busca maneiras de criar espaços e organizar o fluxo e a distribuição dos produtos (BARROS, 2005). Por isso, muitos operadores logísticos (OLs) têm optado pela implantação dessa TI.

Apesar de existir o reconhecimento da utilidade da TI na melhoria das operações das empresas, inclusive das atividades logísticas, seu uso deve ser avaliado para assegurar a eficiente alocação dos recursos de investimento, já que o investimento em TI representa um risco, na medida em que implantar uma ferramenta sem a revisão dos processos da empresa pode ter resultados aquém do esperado (ALBERTIN e ALBERTIN, 2008). Dessa forma, os executivos de Tl devem definir métricas para analisar o investimento realizado e viabilizar o projeto de implantação, para aumentar as chances de sucesso ao final do processo.

Diante do que foi exposto, esse artigo aborda a atividade de armazenagem, com o objetivo da apresentar o método de Ribeiro e Carvalho (2011), aplicando-o a empresas que ofertam serviços logísticos, como os OLs. Para isso, a avaliação da TI proposta utiliza como elemento-chave e norteador da pesquisa o método de Ribeiro (2009), desenvolvido para a avaliação de tecnologia de identificação, mais especificamente, a identificação por rádio frequência (radio frequency identification-RFID).

A avaliação apresentada nesse trabalho é uma adaptação do que foi proposto por Ribeiro (2009), que resultou no método de Ribeiro e Carvalho 
(2011), que tem como foco, nessa nova pesquisa, a avaliação do WMS, dada sua vasta utilização nas empresas da amostra.

A estrutura do artigo é composta por cinco partes: a primeira, a introdução, que se encerra nesse parágrafo; a segunda parte, a transição de um método para outro - Ribeiro (2009) para Ribeiro e Carvalho (2012) e o resultado da revisão de literatura que resultou no método aqui proposto; a terceira parte, a metodologia, que expõe as etapas da pesquisa, o método, a abordagem, técnica de coleta, análise de dados e a amostragem; a quarta parte, o estudo de caso múltiplo, a discussão e comparação dos casos; e a quinta parte, a conclusão.

\section{AVALIAÇÃO DO WMS: ADAPTAÇÃO DO MÉTODO DE RIBEIRO (2009)}

\subsection{TRANSIÇÃO DO MÉTODO DE RIBEIRO (2009) PARA O MÉTODO DE RIBEIRO E CARVALHO (2011)}

O método de Ribeiro e Carvalho (2011) foi desenvolvido a partir do método de avaliação de TI de Ribeiro (2009). Este, por sua vez, resultou de uma composição de atributos de Rogers (1995) e algumas metodologias de implantação de TIs (COBIT, ITIL, CMMI), que deu origem ao Método 1, cujos aspetos considerados são indicados na coluna da esquerda da Figura 1. Este método foi então reorganizado, depois da análise de fontes adicionais da literatura. Particularmente importantes nesse aprimoramento do método foram DeLone e McLean (1992). Esses autores haviam considerado seis categorias de variáveis em seu modelo. Em cada uma delas, listavam um grupo de autores, que foram todos consultados para estruturar o método de Ribeiro (2009) e confirmar algumas variáveis já levantadas no método 1 . Foram revisados trinta e cinco artigos para a construção do novo método. A partir dessa revisão de literatura, foi constituído o método de avaliação de tecnologias de informação de Ribeiro (2009), apresentado na coluna central da Figura 1.

\begin{tabular}{|l|l|l|}
\hline \multicolumn{1}{|c|}{ Método 1 } & \multicolumn{1}{|c|}{ Método Ribeiro (2009) } & \multicolumn{1}{c|}{ Método ora proposto } \\
\hline Atributos & Variáveis organizacionais & Variáveis organizacionais \\
Metodologia COBIT & Variáveis de segurança & Variáveis de segurança \\
Objetivos chave do & Variáveis técnicas & Variáveis técnicas \\
negócio & - Aspectos técnicos & - Aspectos operacionais \\
Fases de avaliação de SI & - Aspectos econômicos & - Aspectos econômicos \\
Segurança & - Aspectos ambientais & \\
Aspectos técnicos & & \\
Aspectos ambientais & & \\
Aspectos econômicos & & \\
\hline
\end{tabular}

Figura 1: Evolução do método de Ribeiro (2009) até o atual

Fonte: elaborada pelas autoras. 
No desenvolvimento do método de Ribeiro e Carvalho (2011), alguns autores merecem destaque pela amplitude de suas contribuições, pois foram importantes para se iniciar o método anterior (RIBEIRO, 2009) e dar continuidade ao aperfeiçoamento ou descoberta de novas variáveis. O Quadro 1 identifica os autores considerados chave para a construção do novo método. A primeira coluna apresenta os autores-chave advindos do método de Ribeiro (2009), enquanto a segunda coluna identifica os autores adicionados ao método de Ribeiro e Carvalho (2011), que teve uma preocupação menor com aspectos técnicos e em que se buscou atender, também, ao usuário e ao alinhamento da $\mathrm{TI}$ ao negócio da empresa.

\begin{tabular}{|l|l|l|l|}
\hline \multicolumn{2}{|c|}{ Autores-chave advindos de Ribeiro (2009) } & \multicolumn{2}{c|}{$\begin{array}{l}\text { Autores-chave adicionados a Ribeiro e } \\
\text { Carvalho (2011) }\end{array}$} \\
\hline \multicolumn{1}{|c|}{ Autor } & \multicolumn{1}{|c|}{ Contribuição } & \multicolumn{1}{c|}{ Autor } & \multicolumn{1}{c|}{ Contribuição } \\
\hline Rogers (1995) & $\begin{array}{l}\text { Elucidou que a taxa de } \\
\text { adoção de uma inovação } \\
\text { pode ser explicada por } \\
\text { cinco atributos: vantagem } \\
\text { relativa, compatibilidade, } \\
\text { complexidade, habilidade } \\
\text { para experimentação e } \\
\text { habilidade para a } \\
\text { observação }\end{array}$ & Alter (1996) & $\begin{array}{l}\text { Analisou a satisfação do } \\
\text { usuário }\end{array}$ \\
\hline $\begin{array}{l}\text { Sonnenwald et } \\
\text { al. (2001) }\end{array}$ & $\begin{array}{l}\text { Incluíram esses cinco } \\
\text { atributos, dividindo-os em: } \\
\text { auxílio nas metas, } \\
\text { qualidade dos resultados, } \\
\text { permanência e destaque } \\
\text { providos pelas inovações }\end{array}$ & $\begin{array}{l}\text { Laurindo } \\
\text { (2008) e } \\
\text { Banzato }\end{array}$ & $\begin{array}{l}\text { Estudaram a associação da } \\
\text { estratégia de TI com a } \\
\text { estratégia de negócio }\end{array}$ \\
\hline $\begin{array}{l}\text { DeLone e } \\
\text { McLean (1992) }\end{array}$ & $\begin{array}{l}\text { Concederam uma } \\
\text { estrutura conceitual } \\
\text { bastante ampla e } \\
\text { completa para o estudo de } \\
\text { avaliação de SI }\end{array}$ & Dias (2009) & $\begin{array}{l}\text { Vincularam o } \\
\text { comportamento do usuário } \\
\text { às características da } \\
\text { tecnologia implantada }\end{array}$ \\
\hline $\begin{array}{l}\text { Beynon- } \\
\text { Davies et al. } \\
\text { (2004) }\end{array}$ & $\begin{array}{l}\text { Dividiram a avaliação de } \\
\text { uma tecnologia nas etapas } \\
\text { de pré-implantação, } \\
\text { implantação, pós- } \\
\text { implantação e post- } \\
\text { mortem }\end{array}$ & Rosa (2010) & $\begin{array}{l}\text { Identificaram a necessidade } \\
\text { do sistema ter condições de } \\
\text { verificar a identidade dos } \\
\text { usuários e esse ter } \\
\text { condições de analisar a } \\
\text { identidade do sistema }\end{array}$ \\
\hline
\end{tabular}

Quadro 1. Autores-chave do método

Fonte: elaborado pelas autoras

A contribuição do método aqui apresentado é atualizar a discussão de Ribeiro (2009), fazer uma releitura de alguns autores, levantando aspectos que não haviam recebido destaque, devido à diferença de foco (agora há interesse espeífico em WMS). Em relação a esse último ponto, o objetivo é o de conceder continuidade à pesquisa, ao aplicar o método a outras TIs. 
Desde as primeiras leituras sobre métodos e modelos de avaliação de TIs e Sls, percebeu-se que, no geral, os autores constroem suas contribuições de forma genérica. Como tem-se observado que as empresas implantam Tls de forma gradual, por ferramentas e não todas TIs simultaneamente, verificou-se a necessidade de construir um método para avaliar uma TI por vez, iniciando-se pela RFID.

Com a aceitação do primeiro método (Ribeiro, 2009), decidiu-se adaptá-lo a outra tecnologia que tem larga implantação no mercado (o WMS), optando-se pela adaptação do método a essa TI, utilizada intensivamente no setor de prestação de serviço logístico.

Conforme afirmado anteriormente, como os artigos sobre métodos e modelos de avaliação de TI eram genéricos, assim como aconteceu na tese de Ribeiro (2009), em que se construiu um método e se realizou uma aplicação à RFID, nesse artigo contribui-se com uma adaptação dos métodos ao WMS. Para realizar essa adaptação do método de Ribeiro (2009) para a avaliação do WMS, algumas variáveis foram excluídas e/ou substituídas, outras adicionadas e as demais mantidas no método novo, de Ribeiro e Carvalho (2011), devido às especificidades da TI analisada, bastante diferentes daquelas da RFID, conforme será visto adiante. As variáveis excluídas e/ou substituídas são destacadas nos parágrafos a seguir, conforme sejam organizacionais, de segurança ou técnicas.

Nas variáveis organizacionais, as avaliações de Beynon-Davies (2004) foram excluídas por não serem consideradas variáveis, nas fases de aplicação do método de avaliação. Além disso, a variável estrutura foi substituída por infraestrutura, uma vez que é representativa da infraestrutura humana (ou organizacional) concebida pelo pessoal de apoio que mantém a TI funcionando.

Todas as variáveis de segurança do método de Ribeiro (2009) foram mantidas. Por fim, no que tange às variáveis técnicas, as variáveis uniformidade, qualidade do equipamento, proximidade com a água, custo da etiqueta, orçamento e risco foram retiradas/substituídas no novo método. Essas variáveis foram excluídas, uma vez que o WMS constitui um software instalado em um computador, diferentemente da RFID, TI que utiliza etiquetas compostas internamente por um front-end, um controlador, EEPROM e hardware de criptografia (AIGNER e FELDHOFER, 2005). No caso da RFID é necessário ter uma uniformidade para haver a mesma captação de informação de todos os produtos do lote; que não podem ter proximidade com água; e conjunto de componentes do sistema necessita ter qualidade para uso. O custo da etiqueta tampouco faz sentido em um método específico para WMS, já que esta TI não usa, diretamente, etiquetas. A variável orçamento foi entendida como variável incluída em custos. Por fim, risco foi substituída por risco econômico.

As variáveis adicionadas são explicitadas nos parágrafos seguintes, conforme sejam organizacionais, de segurança ou técnicas. 
Nas variáveis organizacionais, o atributo satisfação do usuário foi adicionado ao novo método por ser essencial para indicar a satisfação do usuário diante do uso frequente do sistema e sua percepção acerca disso. Deseja-se aferir se ele está satisfeito ou se a adoção da tecnologia não é percebida como vantajosa. Essa variável pode ser medida por meio de quatro subvariáveis, também adicionadas, a saber: aceitação; serviço ao cliente; benefício e participação do usuário. A variável estratégia de mercado foi acrescida ao atributo objetivos chave do negócio por relacionar a $\mathrm{TI}$ com a competitividade da empresa. A última variável organizacional impacto foi acrescentada e dividida em três subvariáveis (representantes das áreas impactadas pelo WMS), as quais são: organizações, relações humanas e comunidades.

Em relação à avaliação nas fases de implantação de TI/SI, advindas do método de Ribeiro (2009), elas foram retiradas das variáveis organizacionais, uma vez que, na implantação de uma TI, elas podem estar relacionadas a outras variáveis. Isso ocorre porque, para cada uma dessas etapas (avaliação estratégica, construtiva, cumulativa e postmortem), pode-se aplicar o método. Dessa forma, as avaliações de Beynon-Davies et al. (2004) foram incluídas no método de Ribeiro e Carvalho (2011) como a melhor forma de avaliação em fases de uma TI e não como um grupo de variáveis propriamente dito.

Entre as variáveis de segurança, as subvariáveis digitalização, controles administrativos, conformidade, previsão e autenticação foram adicionadas. A digitalização foi acrescentada como forma de identificar se o WMS estabelece a comunicação entre cliente e fornecedor. A subvariável controles administrativos refere-se à emissão e monitoramento de diretrizes de segurança, de forma que as normas de segurança sejam sempre aplicadas. A conformidade estabelece uma conexão do software com os requisitos da lei. A previsão identifica os dados em relação ao sistema e, por fim, a autenticação é necessária para verificar a identidade dos usuários do sistema.

Quanto às variáveis técnicas, as variáveis coerência e arquitetura foram adicionadas ao subatributo aspectos técnicos, inserido no grupo dos atributos operacionais. A primeira reflete a coerência entre as informações obtidas pelo WMS e a realidade, enquanto a arquitetura refere-se aos componentes do software e à forma como eles se interligam a outros componentes ou software, por exemplo, o leitor de código de barras ou RFID. A subvariável riscos operacionais também foi acrescentada ao atributo complexidade, referindo-se a riscos de operação, tais como inserção de dados incorretos no sistema ou a falta de atualização. O atributo investimento foi incluído e subdividido em quatro subvariáveis: transacional, informacional, estratégico e infraestrutura, representando os tipos de investimento em WMS. Por fim, a subvariável ambiente técnico, organizacional e macroambiente foi adicionada ao método por fazer referência ao ambiente em que o sistema opera, incluindo práticas e cultura da empresa. 


\subsection{FASES DE IMPLANTAÇÃO DE UMA TECNOLOGIA DE INFORMAÇÃO}

Beynon-Davies et al. (2004) construíram um modelo sobre as lições apreendidas na literatura relacionada a falhas de SI, no qual realizaram uma distinção entre quatro tipos de avaliação de SI, relacionando-as ao modelo de ciclo de vida de um sistema.

Primeiro, a avaliação estratégica, que algumas vezes é referenciada para avaliação de pré-implantação, auxilia na avaliação de investimentos em TI/SI, considerando seu potencial e comparando-os aos custos estimados.

Em seguida, vem a avaliação construtiva que envolve determinar a importância e o valor de um Sl, enquanto ocorre seu próprio desenvolvimento. Essa avaliação pode ser utilizada para fazer mudanças cruciais no projeto de um SI ou para tomar decisões críticas referentes ao grau de abandono do projeto.

O terceiro tipo de avaliação identifica a ocorrência depois que um SI tiver sido implantado e, por isso, é indicado para períodos de pósimplantação, em testes de uso. Seria ideal que essa avaliação cumulativa envolvesse o retorno de custos e benefícios estabelecidos em uma avaliação estratégica depois do período de uso do SI.

Finalmente, a avaliação post-mortem ocorre quando a organização abandona total ou parcialmente o projeto, é uma variação do terceiro tipo.

As avaliações acima descritas representam, portanto, etapas que podem ser definidas para a avaliação do WMS. Sendo assim, o método proposto a seguir pode ser aplicado nas empresas quando da implantação de uma TI (neste caso, o WMS), avaliando a TI em três fases, em caso de sucesso na implantação. Caso contrário, a última avaliação post-mortem também deve ser feita.

\subsection{APRESENTAÇÃO DO MÉTODO DE RIBEIRO E CARVALHO (2011)}

O método de Ribeiro (2009) propôs, a partir da literatura de avaliação de tecnologia, TIs, SIs e WMS, três tipos de variáveis: organizacionais, de segurança e técnicas. No método aqui apresentado propõe-se considerar, na implantação do WMS, as pessoas direta ou indiretamente envolvidas no uso da TI (denominadas usuários), que constam nas variáveis organizacionais; fatores relacionados à segurança da informação, que estão no grupo das variáveis de segurança e características intrínsecas do software, que estão listadas e comentadas nas variáveis técnicas. Essas variáveis e subvariáveis do método, bem como alguns autores que fazem referência a elas, são apresentados a seguir.

\subsubsection{Variáveis organizacionais}

Para Rogers (1995, p. 206), a taxa de adoção de uma inovação pode ser explicada por cinco atributos: vantagem relativa, compatibilidade, complexidade, habilidade para experimentação e habilidade para observação.

(2) Revista Eletrônica de Sistemas de Informação, v. 12, n. 3, set-dez 2013, artigo 3 
O atributo vantagem relativa corresponde ao grau em que cada inovação ultrapassa as práticas atuais quanto à tecnologia e inovação da empresa. O referido atributo pode ser operacionalizado ou mensurado em termos de variáveis, tais como: utilidade para atingir as metas da empresa, qualidade dos resultados pela empresa e permanência e destaque da empresa no mercado (CLEMONS, 1991; DELONE e MCLEAN, 1992; BOYNTON et al., 1994; LEWIS et al., 1995; MOORE e BENBASAT, 1991; AGARWAL e PRASAD, 1997; SONNENWALD et al., 2001).

O atributo compatibilidade incide no grau em que uma inovação é consistente com os valores da empresa que a adota, suas experiências passadas e necessidades, o que inclui metas individuais, do grupo e da instituição, necessidades, cultura e estrutura. Essa discussão, após pesquisa em alguns artigos, pode ser resumida em duas variáveis: comunicação em grupo e experiência com TI (BAILEY e PEARSON, 1983; BOYNTON et al., 1994; SRINIVASAN, 1985; MOORE e BENBASAT, 1991; DELONE e MCLEAN, 1992, 2002; LEWIS et al., 1995; AGARWAL e PRASAD, 1997).

Dias (2009) formulou um modelo de avaliação de SI que teve como foco o comportamento do usuário final - considerado nesse modelo proposto como o atributo "satisfação do usuário" -, concentrando a avaliação nas percepções deste quando do uso do sistema, os valores percebidos, sua disposição em usar, o custo e a confiabilidade que o sistema oferece.

Nesse grupo são destacadas as subvariáveis: aceitação, serviço ao cliente, benefício e participação do usuário. A aceitação de um sistema pelos seus usuários diretos e indiretos depende das seguintes características: valor adicionado; uso do sistema; custo e confiabilidade. Tais características serão explicadas no tópico sobre variáveis técnicas. O serviço ao cliente relaciona-se à qualidade do serviço prestado ao cliente. O benefício, identificado por Oberhofer (1983) e DeLone e McLean (2003), representa as consequências do desempenho do sistema em termos do valor decorrente do seu uso e está associado às mudanças no comportamento dos usuários, influência de outros sistemas ou ao retorno do investimento. A participação do usuário, como o nome supõe, refere-se à participação do usuário quando do uso do sistema.

A observação é um atributo que tem algumas variáveis como a demonstração de resultados, que significa o grau de facilidade em apresentar as consequências, os resultados e os riscos do uso de TI. Esse atributo inclui também visibilidade, ou seja, o grau em que os resultados de uma inovação são visíveis para os outros, se referindo, na literatura, a situações em que a inovação é observada dentro ou fora da organização (SONNENWALD et al., 2001; MOORE e BENBASAT, 1991; AGARWAL e PRASAD, 1997).

Na pesquisa sobre as variáveis relacionadas aos objetivos-chave do negócio, Wetherbe (1979) e Walrad e Moss (1993) consideraram duas abordagens para a avaliação de TI com ênfase na eficiência e na eficácia. 
A primeira refere-se à medição do desempenho com que as entradas são transformadas nas saídas do sistema e tem como foco a atividade de desenvolvimento de sistemas, interno e predominantemente técnico. A ênfase na eficácia equivale a uma medição de como as saídas do sistema atendem aos objetivos, metas e requisitos do sistema e tem como foco o seu impacto na organização em que se insere. Nessa mesma direção, Oberhofer (1983) avalia o SI utilizando os critérios da eficiência e da efetividade, sendo esta última entendida como eficácia. A eficácia consiste na obtenção do efeito desejado, independentemente do esforço e da quantidade de recursos investidos (custos).

Baseados na teoria de Oberhofer (1983), Tallon et al. (2000) apresentaram, alguns anos depois, mais duas variáveis para esse grupo: alcance e estrutura, esta última aqui definida como infraestrutura organizacional. A primeira significa usar a $\mathrm{TI}$ para expandir o alcance geográfico ou o acesso ao cliente, enquanto a estrutura contempla usar a TI para mudar a indústria ou as práticas do mercado.

Ao levar em consideração a importância estratégica da TI, diversos modelos foram apresentados tentando alinhar a estratégia de mercado da empresa à estratégia de TI. Segundo Laurindo (2008), esse alinhamento deve ser desenvolvido e mantido ao longo do tempo, em um processo dinâmico, pois não é possível manter uma vantagem competitiva por meio de uma aplicação específica de TI, já que é cada vez mais fácil copiar essa aplicação e, além disso, as empresas têm usado softwares comuns com frequência. Portanto, ter uma visão estratégica clara para o negócio e para a TI é o ponto de partida para que seja possível um impacto significativo no desempenho da organização. Com o objetivo de alinhar TI e negócio, houve tentativas de criação de modelos mais voltados para a avaliação de aplicações em $\mathrm{TI}$ sob o aspecto de impacto na estratégia da empresa. Neste caso, a estratégia de mercado representa uma subvariável do desenvolvimento de estruturas para mudar a forma de fazer negócio por meio da associação da estratégia de TI com a estratégia de negócio.

Turban et al. (2005) realizaram uma análise específica sobre o impacto da TI nas organizações - considerado como um novo atributo para o método, dividindo-o em três grandes focos, os quais são: nas próprias organizações, nas relações humanas e na comunidade. Em relação ao impacto da TI nas organizações, os autores relatam que a TI é capaz de provocar mudanças na estrutura, distribuição de poderes e supervisão das organizações. Quanto ao impacto nas relações humanas dentro do ambiente de trabalho, a TI pode afetar as percepções e comportamentos dos indivíduos, pois, com sua natureza impessoal e seu potencial, pode também desumanizar e despersonalizar as atividades que foram informatizadas. A última variável é representada pelo impacto da TI nas comunidades reais e virtuais. 


\subsubsection{Variáveis de segurança}

Nesse grupo de variáveis, em relação aos dados contidos em uma Tl, destaca-se a criação do Critério de Avaliação da Segurança de Tecnologia da Informação do Reino Unido (Information Technology Security Evaluation Criteria - ITSEC UK), do qual foram destacadas as variáveis: confidencialidade; integridade - que foi dividida por Ribeiro (2009) em física (proteção física dos recursos de computação) e de dados (prevenção da modificação proibida da informação); disponibilidade e consistência (DEPARTMENT OF TRADE AND INDUSTRY, 1991).

Rosa (2010) e Ribeiro (2009) consideraram os seguintes elementos da política de segurança: disponibilidade (o sistema deve estar disponível de forma que quando o usuário necessitar possa usá-lo); utilização (o sistema deve ser utilizado apenas para determinados objetivos); integridade (o sistema deve estar sempre íntegro e em condições de uso); confidencialidade (dados privados devem ser apresentados somente aos seus donos ou ao grupo por ele liberado); consistência (precisão e atualização dos dados); e autenticação (o sistema deve ter condições de verificar a identidade dos usuários e esse ter condições de analisar a identidade do sistema).

Galvão Júnior e Lima (2010) ressaltam que a segurança da informação precisa de fato ser prioridade para as organizações e deve atender à legislação (conformidade), a fim de contribuir para o crescimento da empresa e o alcance das melhores práticas. Além dessas, há as seguintes subvariáveis de segurança: digitalização, controles administrativos, previsão e autenticação. A digitalização é uma variável identificada por Weill e Aral (2006) e refere-se à digitalização das transações executadas com fornecedores e consumidores. Os controles administrativos, identificados por Turban et al. (2005), correspondem à emissão e monitoramento de diretrizes de segurança, enquanto a previsão consiste na identificação dos resultados em relação ao sistema (WANG e FORGIONNE, 2008).

\subsubsection{Variáveis técnicas}

As variáveis técnicas que fazem parte do método estão divididas em subvariáveis de aspectos operacionais (aspectos técnicos, compatibilidade, complexidade, experimentação e ambiente) e aspectos econômicos (economias geradas, risco econômico, custos e investimento). No entanto, estes últimos, apesar de terem sido mais destacados em relação à ênfase dada a eles no método de Ribeiro (2009), foram apenas citados na avaliação uma vez que um estudo mais aprofundado dessas variáveis econômicas exigiria uma dedicação mais apurada e restrita a cada método de avaliação econômica.

\section{Aspectos operacionais}

Para Alter (1996), a subvariável desempenho procura verificar como o sistema opera e se opera corretamente. Como ele depende do equilíbrio entre os seus componentes, melhorar o desempenho de apenas uma de 
suas partes pode não afetar os resultados se por acaso as outras partes se mantiverem inalteradas. Lima (2010) reforça a importância dos indicadores de desempenho, os quais permitem melhorias na produtividade e modernização dos procedimentos e rotinas tradicionais, à medida que eles evidenciam os pontos fortes e fracos existentes e a resposta rápida dos gestores e técnicos.

Leite (2007) aborda os SIS sob o ponto de vista da qualidade. Esse mesmo autor destaca que um 5 I deve refletir o que ocorre em uma organização, como um espelho, enfatizando que ele deve ser coerente com a realidade (coerência), isto é, as informações que o sistema contém devem refletir a realidade.

No que se refere à qualidade dos SIs em termos de software, Chermont (2001) destaca que ela pode ser definida como o conjunto de características a serem satisfeitas em um determinado grau, para que o software atenda às necessidades de seus usuários. Ao se referir à qualidade, a rapidez de um sistema reflete a velocidade com que uma informação é liberada para os usuários e no exato momento em que eles necessitam dela e seu grau deve ser definido pelos usuários. Isso é extremamente razoável quando se considera que as necessidades e urgência dos usuários são dinâmicas. Na definição de uma métrica de rapidez, deve-se estabelecer a diferença entre a disponibilidade da informação para o sistema e a disponibilidade da informação para o usuário. Essa métrica também relaciona-se à subvariável aceitação, incluída na variável satisfação dos usuários no item dos aspectos organizacionais. Delone e Mclean (1992) também contribuíram na discussão dessa subvariável, considerando-a como tempo reduzido no processamento de informação.

Alter (1996) propôs um método para avaliar os SIs denominado análise centrada no trabalho (work-centered analysis - WCA), o qual inclui a informação, a TI, esforços dos participantes e o processo de negócios. Nessa análise, os Sis não são considerados apenas como sistemas puramente técnicos, mas levam em consideração também o porquê desses sistemas existirem. $O$ autor apresentou cinco perspectivas segundo as quais um SI pode ser analisado, são elas: desempenho, arquitetura, infraestrutura, contexto e riscos. A primeira subvariável já foi comentada acima, as demais serão comentadas a seguir.

Segundo Turban et al. (2005), a arquitetura de TI delineia a forma como devem ser utilizados os recursos de informática da organização para realizar sua missão, abrangendo os aspectos técnicos e gerenciais desses recursos. Os aspectos técnicos englobam o hardware e sistemas operacionais, redes, dados e sistemas de gerenciamento de dados e software de aplicações. A arquitetura especifica como um $\mathbf{S I}$ atual ou proposto opera mecanicamente, apresentando seus componentes, a maneira como eles estão unidos e como operam de maneira sistêmica. O aspecto básico da arquitetura é a decomposição sucessiva, ou seja, divide-se os componentes nas suas unidades mais básicas até que a pessoa que está realizando 
a análise entenda suficientemente a arquitetura. Já a infraestrutura é identificada como o provimento de serviços compartilhados por meio de equipamentos de informática, redes e a estrutura de apoio (TURBAN et al., 2005).

A perspectiva do contexto avalia o ambiente técnico e organizacional dentro do qual o sistema opera, incluindo acionistas, assuntos competitivos e reguladores externos à empresa, além de políticas, práticas e a cultura da organização. Os riscos, por fim, consistem em eventos previsíveis cuja ocorrência poderia resultar em degradação ou falha do sistema (OBERHOFER, 1983).

Quanto às subvariáveis relacionadas à compatibilidade - confiabilidade do sistema e tempo de resposta - DeLone e McLean (1992) e Sonnenwald et al. (2001) contribuíram para essa revisão. Dias (2009) propôs um modelo de aceitação do SI, que foi apresentado no tópico que considera os aspectos organizacionais. Nesse modelo, o autor destaca que o nível de uso do sistema está associado aos princípios da utilidade, usabilidade e da qualidade, que se desdobram em fatores e subfatores. Entre esses subfatores, tem-se os denominados qualidade do sistema e confiabilidade, mas somente esse último foi considerado no método.

Segundo Ribeiro (2009), a complexidade se refere à dificuldade percebida no aprendizado para uso de um novo sistema ou tecnologia. Quando um sistema demonstra ser difícil de entender, aprender ou usar, este não é adotado. As pesquisas na área da engenharia e uso de sistemas enfatizam a importância de reduzir a complexidade na interação homem-computador. Com o atributo complexidade houve uma divisão em: facilidade do uso e aprendizado do sistema.

A utilidade mede e avalia o valor dos outputs do sistema, tendo como variáveis a precisão e o recall, cujo uso dependerá da abordagem a ser definida. A precisão foi abordada no tópico das variáveis técnicas. Wang e Forgione (2008) contribuíram para o método com o atributo complexidade com as subvariáveis: facilidade do uso e facilidade do entendimento do sistema.

Os riscos operacionais representam uma subvariável técnica do método. Eles consistem em eventos previsíveis cuja ocorrência poderia resultar em degradação ou falha do sistema. Relacionam-se a três aspectos principais, conforme Souza et al. (2005): acidentes e mau funcionamento (bugs, falhas humanas), crime de computador (hackers, vírus, falsificações) e falhas de projeto. Stoneburner et al. (2002) acrescentam que a avaliação dos riscos é o primeiro processo na metodologia de gerenciamento de risco. Esses autores definem, ainda, gestão de riscos como o processo que permite que gerentes de TI equilibrem os custos operacionais e econômicos das medidas de proteção e obtenham ganhos de capacidade de missão por proteger os sistemas de TI/SI e dados que suportam as missões de suas organizações. Essa subvariável foi definida no método como risco econômico, dentro da variável aspectos econômicos. 
A habilidade em experimentação foi dividida em facilidade de recuperação de dados (ou de reverter operações usando sistemas) e esforço para uso do sistema, além dos custos envolvidos nessas operações. Destaca-se que, na análise proposta por Ribeiro (2009) no que tange à habilidade em experimentação, foi acrescentada a subvariável aceitação. Entretanto, no método de Ribeiro e Carvalho (2011), essa subvariável foi acrescentada no grupo das variáveis organizacionais.

No que tange à facilidade, Sedera et al. (2004) apresentaram alguns grupos de variáveis influenciados pelo modelo de DeLone e McLean (1992), classificando facilidade do uso e facilidade de aprendizado do sistema no grupo de qualidade do sistema. Sabherwal et al. (2006) contribuíram com seu trabalho para o atributo complexidade quando as variáveis facilidade de uso (que eles consideraram no construto qualidade do sistema) e esforço para uso do sistema (tratada no construto uso do sistema) foram incluídas no modelo desenvolvido pelos autores. Essas variáveis foram explicitadas anteriormente. Petter e McLean (2009) identificaram no construto qualidade do sistema a subvariável facilidade do uso, contribuindo, também, para o método de avaliação de Ribeiro (2009).

Wang e Forgionne (2008) usaram o modelo de avaliação de teoria da decisão e o critério do resultado para avaliar os resultados recuperados para ambos os usuários (utilidade e aprendizado) e sistema (precisão e recall). De acordo com os autores, "o aprendizado do usuário representa o seu progresso em entender o problema atual ou adquirir habilidades para - futuro e para a tomada de decisão como um resultado da busca de informação".

Por fim, o atributo ambiente técnico, organizacional e macroambiente refere-se a um levantamento minucioso de cada componente da infraestrutura da empresa, tendo em vista suas reais demandas. Assim, permite-se avaliar o ambiente em produção fornecendo um diagnóstico detalhado para a adoção das melhores práticas e tecnologias que agregarão valor e que levarão a um melhor desempenho do negócio da empresa. Além disso, a partir da avaliação do ambiente de TI e da classificação dos riscos é possível desenvolver um plano de ação para mitigar deficiências críticas, ações de redução de custos e melhorias de rápida implantação.

\section{Aspectos econômicos}

Os aspectos econômicos das variáveis técnicas são considerados um dos elos principais na implantação de uma TI. A intenção da criação do tópico dos aspectos econômicos foi demonstrar que, apesar da necessidade de se utilizar técnicas precisas de análise econômica quando uma empresa deseja implantar uma nova TI, é importante considerar aspectos além do financeiro. Os aspectos econômicos foram divididos em desenvolvimento e investimento. 
Quanto à viabilidade, a subvariável economias geradas representa as economias advindas do uso contínuo do software. O risco econômico refere-se ao fato da implantação da tecnologia não gerar retorno financeiro ou ser de manutenção cara. Quanto à subvariável custos, Macedo e Bengio (2010) apresentam uma divisão em dois grupos: custos diretos e custos indiretos. O primeiro custo é frequentemente subestimado e pode incluir hardware adicional inesperado, instalação e configuração. 0 segundo, no entanto, é mais significativo e está associado com as tentativas da administração para capitalizar o maior potencial do sistema nos negócios e níveis de projeto.

DeLone e McLean (1992) ao investigarem a variável denominada impacto organizacional no seu método apresentaram algumas variáveis em comum com os aspectos econômicos do método proposto nesse artigo, como: custo operacional (custos), ganhos de produtividade, crescimento dos lucros e incremento nas receitas (lucratividade).

Weill e Aral (2006) identificam quatro classificações de investimentos em $\mathrm{TI}$ de acordo com seus objetivos, as quais são: transacional (reduzir custos e melhorar a eficiência); informacional (fornecer informações para contabilidade, relatórios e análises); estratégica (conquistar vantagem competitiva) e infraestrutura (prover serviços compartilhados). Verifica-se, então, que independentemente do tipo de investimento realizado pelas empresas, o foco principal é sempre a redução de custos e, obviamente, o aumento do lucro, objetivando agregar valor ao seu produto ou serviço para obter destaque maior perante seus concorrentes.

A seguir, o Quadro 2 apresenta todas as variáveis do método de Ribeiro e Carvalho (2011). Nota-se que elas estão divididas em organizacionais, de segurança e técnicas. Para uma melhor formatação, as variáveis dividem-se em atributos dos quais derivam as subvariáveis. Os atributos e/ou subvariáveis destacados com um asterisco (*) representam os (as) que foram adicionados (as) ao novo método. As demais são variáveis mantidas do método anterior.

\begin{tabular}{|l|l|}
\hline \multicolumn{2}{|c|}{ Variáveis organizacionais } \\
\hline \multirow{4}{*}{ Vantributos } & \multicolumn{1}{c|}{ Subvariáveis } \\
\hline \multirow{2}{*}{ Compatibilidade } & Auxílio nas metas \\
\cline { 2 - 2 } & Qualidade dos resultados \\
\cline { 2 - 2 } & Permanência e destaque \\
\hline \multirow{2}{*}{ Satisfação do usuário* } & Comunicação em grupo \\
\cline { 2 - 2 } & Experiência com TI \\
\hline & Aceitação* \\
\cline { 2 - 2 } & Serviço ao cliente* \\
\cline { 2 - 2 } & Benefício* \\
\cline { 2 - 2 } & Participação do usuário* \\
\hline Observação & Visibilidade \\
\hline Objetivos chave do negócio & Eficiência \\
\hline
\end{tabular}

14 Revista Eletrônica de Sistemas de Informação, v. 12, n. 3, set-dez 2013, artigo 30 doi:10.5329/RESI.2013.1203003 


\begin{tabular}{|c|c|}
\hline & Eficácia \\
\hline & Estratégia de mercado* \\
\hline & Infraestrutura* \\
\hline & Alcance \\
\hline Impacto* & Impacto na organização* \\
\hline & Impacto nas relações humanas* \\
\hline & Impacto na comunidade* \\
\hline Variáveis de segurança & \\
\hline Atributos & Subvariáveis \\
\hline Controle de dados e informação & Confidencialidade \\
\hline & Integridade física \\
\hline & Integridade dos dados \\
\hline & Disponibilidade \\
\hline & Digitalização* \\
\hline & Controles administrativos* \\
\hline & Consistência \\
\hline & Conformidade* \\
\hline & Previsão* \\
\hline & Autenticação* \\
\hline Variáveis técnicas & \\
\hline Atributos & Subvariáveis \\
\hline Aspectos operacionais & \\
\hline Aspectos técnicos & Desempenho \\
\hline & Coerência* \\
\hline & Rapidez \\
\hline & Infraestrutura* \\
\hline & Arquitetura* \\
\hline Compatibilidade & Confiabilidade e tempo de resposta \\
\hline Complexidade & Facilidade do uso do sistema \\
\hline & Facilidade de aprendizado do sistema \\
\hline & Risco operacional* \\
\hline Experimentação & Facilidade de recuperação dos dados \\
\hline & Esforço para uso do sistema \\
\hline Ambiente técnico, organizaciona & nbiente* \\
\hline Aspectos econômicos & \\
\hline Viabilidade & Economias geradas \\
\hline & Risco econômico \\
\hline & Custos \\
\hline Investimento* & Transacional* \\
\hline & Informacional* \\
\hline & Estratégico* \\
\hline & Infraestrutura* \\
\hline
\end{tabular}

Quadro 2. Variáveis do método de Ribeiro e Carvalho (2011)

Fonte: elaborado pelas autoras 


\section{METODOLOGIA}

Para o desenvolvimento desse trabalho, o método de pesquisa escolhido foi o estudo de caso, definido por Bryman (1989) como um exame detalhado de uma empresa ou número pequeno de casos, com a unidade de análise sendo, geralmente, a organização. Entretanto, tal unidade pode se estender a departamentos entre redes de organizações ou redes interorganizacionais, explica o referido autor.

No sentido de proporcionar uma visão geral das variáveis principais a serem consideradas na implantação de Tls por parte das empresas, este artigo sugeriu uma adaptação do método de Ribeiro (2009) para esse tipo de avaliação que resultou no método de Ribeiro e Carvalho (2011). Assim, ao tomar como base o método de Ribeiro (2009) para o desenvolvimento dessa pesquisa, quanto à fase de união de teoria e caso, esse estudo caracteriza-se pela indução analítica. De acordo com Yin (2001), utiliza uma teoria previamente desenvolvida como modelo com o qual se deve comparar os resultados empíricos do estudo de caso.

A abordagem de pesquisa utilizada foi a qualitativa que, conforme Bryman (1989), possui ênfase na perspectiva individual de quem está sendo estudado, além de significar uma forma de saber diferente e uma nova forma de conhecimento.

A técnica de coleta de dados utilizada constitui um método baseado em perguntas diretas. Para isso, utilizou-se o questionário, instrumento constituído por um conjunto de perguntas ordenadas formuladas pelo pesquisador e que foi respondido pelo sujeito pesquisado que, neste caso, resume-se a gestores de OLs.

A amostra foi composta por três OLs localizados na região de São Paulo. Os estudos de caso a serem apresentados foram baseados nas respostas dos questionários enviados a cada um dos OLs, entre os meses de abril e junho do ano de 2012. Destaca-se que os questionários foram enviados via e-mail e as dúvidas obtidas a partir do preenchimento também foram solucionadas de forma online ou via ligação telefônica.

A escolha das perguntas foi baseada no método de avaliação do WMS de Ribeiro e Carvalho (2011). As variáveis foram divididas em organizacionais, de segurança e técnicas, como já mencionado. Para a análise das variáveis, elas (ou suas subvariáveis) foram enquadradas em perguntas de múltipla escolha que incluíam uma escala cuja pontuação variava entre 1 e 5 ( 1 = muito baixo; 2 = baixo; 3 = médio; 4 = alto; 5 = muito alto). O método teve uma validação externa que, segundo Maffezolli e Bohes (2008, p. 1) “dedica-se a estabelecer o domínio sobre o qual as descobertas podem ser generalizáveis e está intimamente relacionada à possibilidade de replicação do estudo." 


\section{RESULTADOS E DISCUSSÃO}

\subsection{Estudos de caso: apresentação das empresas}

Como forma de validar o método de Ribeiro e Carvalho (2011), aplicou-se o referido método em três OLs, aqui tratados como empresas $\mathrm{A}, \mathrm{B}$ e C. A escolha das empresas foi feita considerando a maior probabilidade de obtenção de resposta rápida dos questionários preenchidos, tendo em vista a realização de estudos de casos anteriores nessas mesmas organizações.

A empresa A teve como respondente um funcionário que trabalha há onze anos como sócio-diretor na organização. Segundo informações contidas em suas respostas, e de acordo com a classificação do BNDES, o OL é classificado como média empresa, possuindo cerca de 220 funcionários na instalação estudada. Esse OL não possui atuação fora do país e está há dezesseis anos no mercado, tendo se especializado em três atividades da logística: recebimento, armazenagem e expedição.

A empresa $\mathrm{B}$ teve como respondente um funcionário que trabalha há quatro anos na organização, primeiramente no cargo de engenheiro de processos e, atualmente, como gerente de engenharia logística. Segundo informações contidas em suas respostas, o OL é classificado como médiagrande empresa (no Brasil) e grande empresa em escala mundial, considerando suas atuações fora do país. O OL possui cerca de 2300 funcionários no Brasil, está há oito anos no mercado brasileiro e é especialista nas seguintes atividades logísticas: transporte, armazenagem, operações inhouse e desenvolvimento de processos logísticos.

Por fim, a empresa $C$ teve como respondente um funcionário que trabalha há dois anos na organização como gerente de projetos. De acordo com suas respostas, o OL é classificado como média empresa com atuação em mais de vinte países. Tem cerca de 1.000 funcionários no Brasil, oferecendo soluções de logística integrada em serviços voltados para armazenagem, embalagem, distribuição, transporte, limpeza, serviços de valor agregado, além de operações portuárias. A empresa C trabalha, ainda, com vários setores, a saber: bens de consumo e indústria, líquidos, química, automobilística, varejo, carga geral, commodities, entre outros.

\subsubsection{Comparação dos casos}

Ao responder o questionário, foi solicitado aos respondentes que indicassem uma nota, variando de 1 a 5 , a cada uma das subvariáveis do método, de acordo com a capacidade do WMS atender ou não ao conceito apresentado a eles.

Para fazer uma análise correta, as subvariáveis consideradas negativas foram tratadas da seguinte forma na escala de 1 a 5: aquelas que obtiveram pontuação 1 (muito baixo) referem-se a uma característica positiva e, por isso, as suas pontuações foram substituídas por 5 . No lado 
oposto, as que foram pontuadas com pontuação 5 tiveram suas pontuações trocadas por 1. De forma análoga, a pontuação 4 tornou-se 2 e vice-versa e, por fim, a pontuação 3 manteve-se inalterada. Essas subvariáveis foram definidas como negativas, porque, quanto maior a pontuação a elas concedida, maior o impacto negativo sobre o desempenho do software. Assim, no método, as variáveis organizacionais (representadas por impacto nas organizações, nas relações humanas e na comunidade), a de segurança (digitalização) e as técnicas (risco operacional, esforço para uso, risco económico e custos) foram identificadas como variáveis de escala invertida (negativas).

As subvariáveis organizacionais e suas respectivas pontuações são apresentadas na Figura 2. Nota-se que para a empresa $\mathrm{A}$, as maiores pontuações foram concedidas às variáveis qualidade nos resultados, permanência e destaque, serviço ao cliente, eficiência e impacto na comunidade. Para a empresa B, experiência com $\mathrm{Tl}$, confiabilidade e tempo de resposta, serviço ao cliente, benefício, visibilidade e infraestrutura foram as variáveis com melhores pontuações. A empresa $C$, por sua vez, concedeu melhores notas para confiabilidade e eficiência.

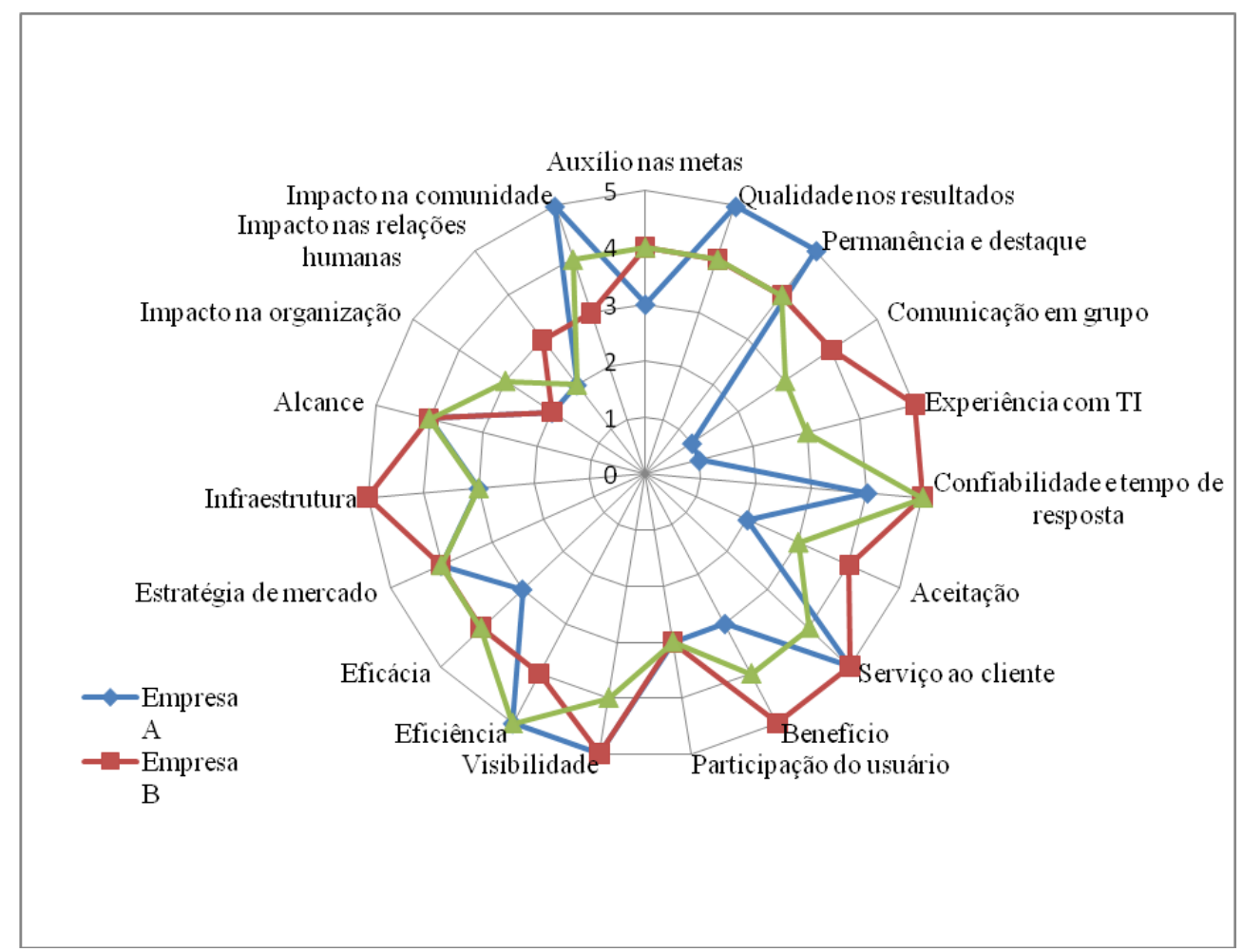

Figura 2. Comparação das subvariáveis organizacionais para as empresas A, B e C

Fonte: elaborada pelas autoras

A seguir, a Figura 3 ilustra as pontuações concedidas às subvariáveis de segurança pelas empresas $\mathrm{A}, \mathrm{B}$ e C. Para a empresa $\mathrm{A}$, digitalização, conformidade, previsão e autenticação foram as variáveis com maior pontuação. A empresa B concedeu pontuação máxima para confidencialidade, integridade física, integridade dos dados, disponibilidade, controles administrativos, consistência e conformidade, enquanto para o WMS da 
empresa $\mathrm{C}$ as maiores notas foram das variáveis integridade dos dados e disponibilidade.

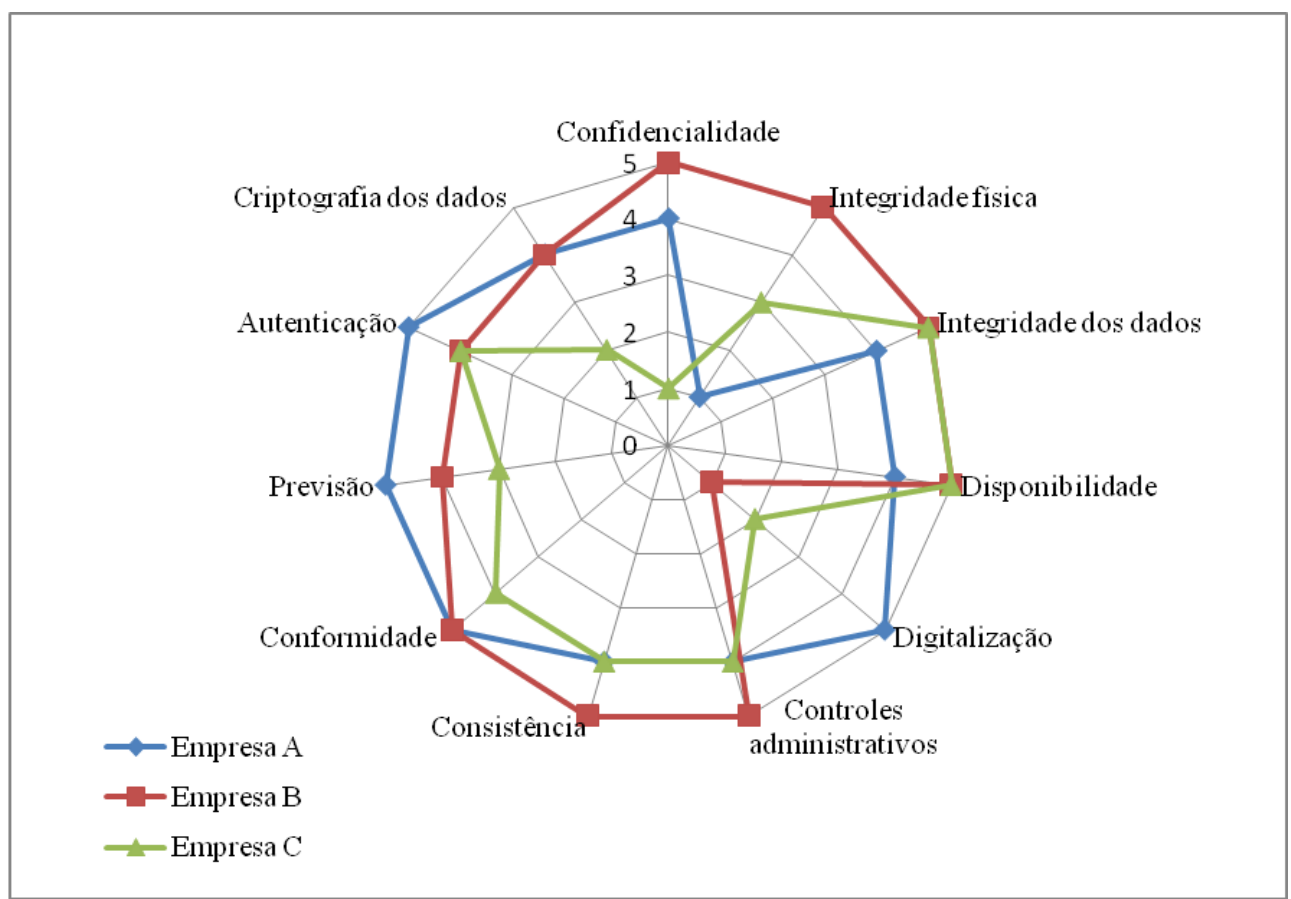

Figura 3. Comparação das subvariáveis de segurança para as Empresas A, B e C Fonte: elaborada pelas autoras

Por fim, a Figura 4 relaciona as pontuações dadas aos atributos das variáveis técnicas pelas empresas $\mathrm{A}, \mathrm{B}$ e C. A variável desempenho foi a única que obteve nota máxima pela empresa A. A empresa B concedeu a maior nota para a variável coerência e a empresa C para integridade dos dados e disponibilidade. 


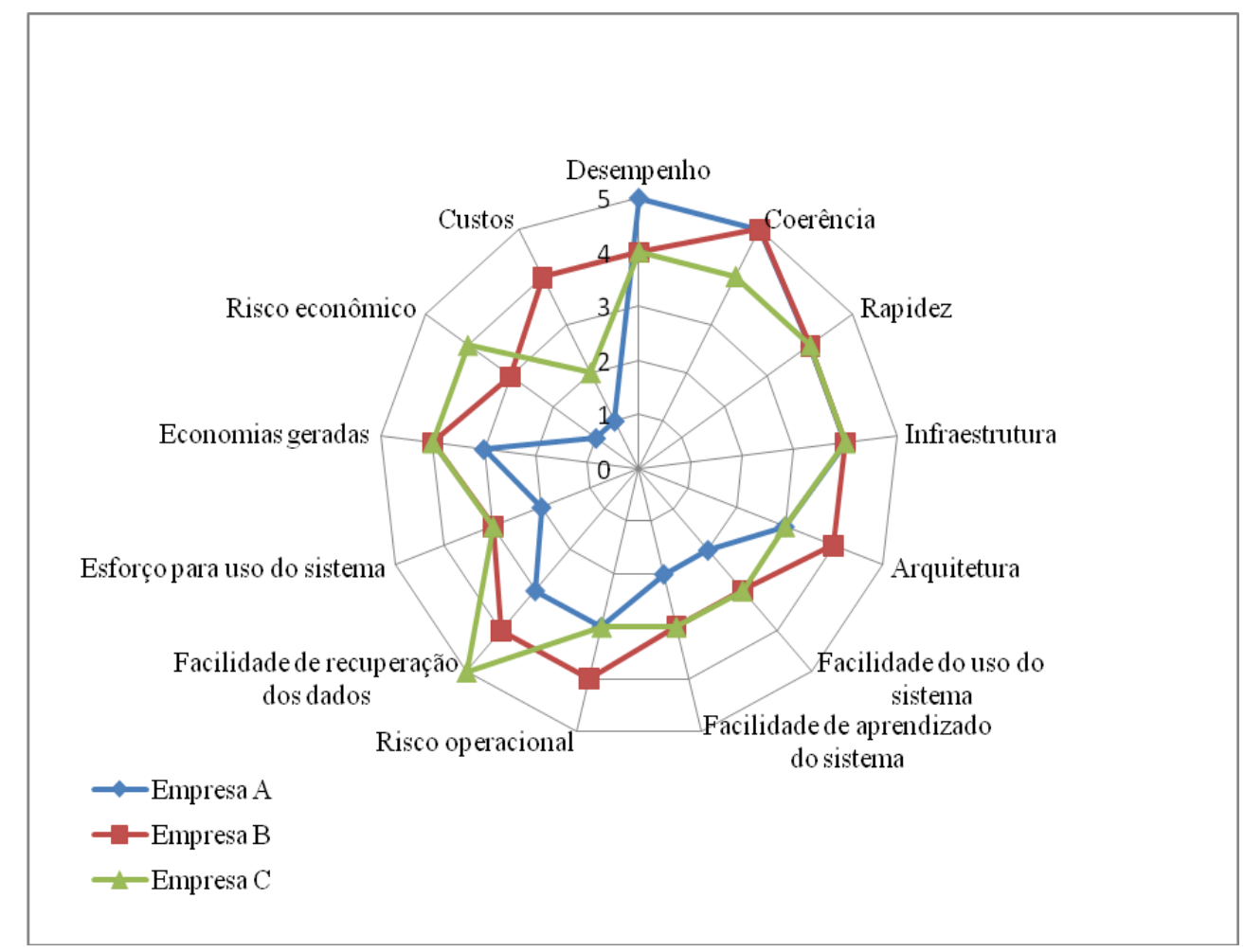

Figura 4. Comparação das subvariáveis técnicas para as Empresas A, B e C

Fonte: elaborada pelas autoras

Ao se valer do número total de subvariáveis em cada grupo de variáveis e considerar o fato de que a pontuação máxima que poderia ser atribuída a cada uma das subvariáveis é 5 , tem-se que a maior soma $(\Sigma)$ a ser obtida por um WMS que atenda perfeitamente a todas essas variáveis será 95, 55 e 65 para as variáveis organizacionais, de segurança e técnicas, respectivamente.

A partir da identificação das variáveis que obtiveram pontuação máxima (5) em cada um dos estudos de caso, pode-se considerar, de acordo com a quantidade de notas máximas, o valor percentual em que o WMS atende plenamente aos grupos de variáveis do método: organizacionais, de segurança e técnicas. Como exemplo, ao considerar que para a empresa A seis das subvariáveis organizacionais, em um total de dezenove, obtiveram pontuação máxima (valor 5) conclui-se que em $31,6 \%$ das variáveis organizacionais o WMS atende perfeitamente a esse OL. Esse valor se repete para a empresa B. Por outro lado, o WMS atende plenamente à empresa $C$, nas variáveis organizacionais do método, apenas em torno de $10,5 \%$. As demais percentagens são mostradas no Quadro 3. 


\begin{tabular}{|c|c|c|c|c|c|c|c|}
\hline \multirow{3}{*}{ Tipo de variável } & \multirow{3}{*}{$\begin{array}{l}\text { Pontuação } \\
\text { máxima }\end{array}$} & \multicolumn{6}{|c|}{$\Sigma$ Notas das empresas } \\
\hline & & \multicolumn{2}{|c|}{ Empresa A } & \multicolumn{2}{|c|}{ Empresa B } & \multicolumn{2}{|c|}{ Empresa C } \\
\hline & & $\begin{array}{c}\Sigma \text { notas } \\
\text { máx. } * 5\end{array}$ & $\%$ & $\begin{array}{l}\Sigma \text { notas } \\
\text { máx. } * 5\end{array}$ & $\%$ & $\begin{array}{c}\Sigma \text { notas } \\
\text { máx. } * 5\end{array}$ & $\%$ \\
\hline $\begin{array}{l}\Sigma \text { variáveis } \\
\text { organizacionais }\end{array}$ & $19 * 5=95$ & $6 * 5=30$ & 31,6 & $6 * 5=30$ & 31,6 & $2 * 5=10$ & 10,5 \\
\hline $\begin{array}{l}\Sigma \text { variáveis de } \\
\text { segurança }\end{array}$ & $11 * 5=55$ & $4 * 5=20$ & 36,4 & $7 * 5=35$ & 63,6 & $2 * 5=10$ & 18,2 \\
\hline$\Sigma$ variáveis técnicas & $13 * 5=65$ & $2 * 10=10$ & 15,4 & $1 * 10=10$ & 7,7 & $1 * 10=10$ & 7,7 \\
\hline
\end{tabular}

Quadro 3. Comparação entre as notas máximas concedidas pelas empresas A, B e C

Fonte: elaborado pelas autoras

De forma análoga ao exemplo anterior, conclui-se que o WMS atende perfeitamente à empresa A em $36,4 \%$ das variáveis de segurança, enquanto para a Empresa B esse número se eleva para 63,6\%. Já para a Empresa $\mathrm{C}$, esse número cai para $18,2 \%$. Para as variáveis técnicas, o WMS atende por completo a $15,4 \%$ (organizacionais) no caso da empresa A e $7,7 \%$ às empresas B e C. Ao se considerar a amostra em estudo, esses últimos números revelam a importância da alta customização do WMS para um funcionamento adequado de acordo com as características de cada empresa.

Como análise adicional, o Quadro 4 apresenta os somatórios resultantes e percentagens obtidas ao analisar o WMS considerando o conjunto de grupos de variáveis e todas as notas dadas (não somente as máximas). Como exemplo, ao considerar que há um total de dezenove variáveis organizacionais e que o somatório das notas dadas às variáveis desse quesito, no caso da empresa $\mathrm{A}$ foi de 65 , o software atende às variáveis organizacionais em $68,4 \%$.

\begin{tabular}{|c|c|c|c|c|c|c|c|}
\hline \multirow{3}{*}{ Tipo de variável } & \multirow{3}{*}{$\Sigma$} & \multicolumn{6}{|c|}{$\Sigma$ Notas das empresas } \\
\hline & & \multicolumn{2}{|c|}{ Empresa A } & \multicolumn{2}{|c|}{ Empresa B } & \multicolumn{2}{|c|}{ Empresa C } \\
\hline & & $\Sigma$ & $\%$ & $\Sigma$ & $\%$ & $\Sigma$ & $\%$ \\
\hline$\Sigma$ notas das variáveis organizacionais & $19 * 5=95$ & 65 & 68,4 & 77 & 81,1 & 70 & 73,7 \\
\hline$\Sigma$ notas das variáveis de segurança & $11 * 5=55$ & 45 & 81,8 & 48 & 87,3 & 37 & 67,3 \\
\hline$\Sigma$ notas das variáveis técnicas & $13 * 5=65$ & 38 & 58,5 & 49 & 75,4 & 46 & 70,8 \\
\hline
\end{tabular}

Quadro 4. Somatório das notas e percentagens resultantes das subvariáveis do método

Fonte: elaborado pelas autoras

Analogamente ao exemplo anterior, o WMS atende a empresa B em $81,1 \%$ e C em $73,7 \%$. Quanto às necessidades de segurança, o WMS atende às empresas nas seguintes percentagens: $81,8 \%$ (empresa A), $87,3 \%$ (empresa B) e $67,3 \%$ (empresa C). Em relação às variáveis técnicas, aproximadamente $58,5 \%$ para a empresa A, $75,4 \%$ para a 
empresa B e 70,8\% para a empresa C dão suporte técnico suficiente aos OLS.

As figuras e os quadros apresentados anteriormente demonstram, de maneira mais visual, as pontuações concedidas às variáveis do método. A partir da análise das subvariáveis citadas, conclui-se que o WMS atende melhor à empresa B, uma vez que as somas referentes às variáveis organizacionais, de segurança e técnicas são todas maiores que as somas das empresas A e C. Tal fato pode ser analisado com base na informação que a empresa B desenvolve seu próprio software, o que faz com que os requisitos da tecnologia tenham sido criados para melhor atender às necessidades do OL e, dessa forma, o software fica ainda mais customizado.

Por fim, o WMS atende as empresas A, B e C, em média, em $74,4 \%$ das variáveis organizacionais, $78,7 \%$ das variáveis de segurança e $68,2 \%$ das variáveis técnicas. Diante desses resultados, ao unir os três tipos de variáveis, o WMS atende às empresas em torno de $73,8 \%$.

\section{CONCLUSÃO}

A logística compreende diversas atividades executadas dentro ou fora de uma empresa, envolvendo armazenagem, estoque, transporte, distribuição, entre outras. Tais atividades representam um dos maiores elementos de custo de uma empresa e, por isso, muitas organizações têm utilizado, em grande escala, os serviços prestados por OLs e outros prestadores de serviços logísticos (PSLS). Estes, por sua vez, destacam-se pela maior especialização e rápida evolução tecnológica proporcionada, uma das principais causas da disseminação da contratação desses terceiros.

O WMS é uma das TIs mais utilizadas por OLs e PSLs e concede como vantagens do seu uso a realização do controle físico e fiscal, e a possibilidade de realizar as atividades de um armazém. Essas atividades de recebimento, armazenamento e separação de produtos podem ser avaliadas de várias maneiras, considerando regras como validade, peso, volume, tipo de movimentação, código de produto, data de entrada e saída, entre outras. Por outro lado, o WMS também apresenta algumas desvantagens, dentre as quais está o alto custo de implantação.

A pesquisa - realizada com OLs localizados na região de São Paulo permitiu concluir que a avaliação do aspecto organizacional voltado para o usuário de um sistema deve ser considerada essencial na implantação de uma $\mathrm{Tl}$, pois representa um efeito indireto a partir dos benefícios percebidos, além de garantir a continuidade do uso do WMS pela empresa. Isso demonstra que as análises tradicionais focadas apenas em aspectos financeiros são entendidas como formas insuficientes para realizar a avaliação dos ganhos advindos da implantação de tecnologias diferentes. Assim, a satisfação do usuário torna-se essencial para avaliar os sistemas em si, pois os usuários estão diretamente relacionados à produtividade individual e da organização em que atuam. 
Diante das análises listadas no tópico das comparações, pode-se concluir com a aplicação do método alguns pontos discutidos na revisão bibliográfica. Ao se considerar os três grupos de variáveis (organizacionais, de segurança e técnicas), o WMS teve melhor desempenho nos aspectos de segurança. Isso ocorre porque uma das necessidades primordiais da atividade de armazenagem é a precisão das informações, ou seja, a função de alocação do WMS só pode ser realizada a contento se ele obtiver os dados corretos e completos dos produtos recebidos nas docas dos CDs.

A empresa B concedeu a melhor avaliação do WMS quanto aos aspectos organizacionais, de segurança e técnicos, o que pode ser explicado pelo fato de ela ter utilizado uma equipe interna para desenvolvimento do software. Com isso, a empresa pôde desenvolver a TI customizada, ou seja, o WMS foi estruturado de acordo com as necessidades da empresa e suas características gerenciais, sua infraestrutura e sua arquitetura de informação e TI.

Na maioria das comparações, a empresa C obteve uma pontuação baixa em relação às variáveis e subvariáveis, o que pode ser explicado pelo fato de a empresa ter, inicialmente, optado pela implantação do WMS de um fornecedor. Como a empresa não obteve sucesso em sua implantação, ela optou por se adaptar e integrar o WMS do grupo (considerando suas outras filiais localizadas fora do país). Essa transição pode ter influenciado negativamente a percepção de desempenho do software, devido às intensas customizações e adaptações realizadas. Como essas TIs possuem um limite de horas para customização, essas interferências devem ter comprometido a estrutura do software e de seu desempenho, como consequência.

Ao se considerar as três variáveis em conjunto, o WMS também obteve uma melhor avaliação na empresa B, o que pode ser explicado como afirmado anteriormente, por a empresa ter desenvolvido o software internamente.

As subvariáveis comunicação em grupo e experiência com T/ (no grupo das variáveis organizacionais) foram as que obtiveram maiores discrepâncias nas avaliações. Essa discrepância pode ser explicada pelo fato dessas subvariáveis serem derivadas de características intrínsecas a cada uma das empresas: auxílio na troca de informação dentro da empresa e experiência passada da empresa com TIs. Além disso, a existência de outras TIs pode auxiliar na troca de informações e conceder experiência aos usuários, facilitando a adaptação a novas tecnologias implantadas na empresa. Com esse ritmo de implantação mais frequente de Tls, a organização possui uma metodologia que a auxilia a se estruturar para novas TIs e para ofertar treinamento aos seus funcionários sempre que for necessário.

As subvariáveis confidencialidade, integração física e digitalização (no grupo das variáveis de segurança) obtiveram disparidade nas avaliações. Essa diferença deve ser explicada pelas particularidades do software 
para atender aos objetivos das empresas. O mesmo ocorreu com as subvariáveis risco econômico e custos, o que pode ser explicado pelo fato de estarem diretamente relacionadas ao processo de implantação em si do WMS e se esse processo é feito via terceiro ou desenvolvido pela própria empresa.

Apesar do alto custo de implantação e da necessidade de customização, o WMS apresenta uma percentagem elevada de atendimento às variáveis propostas no método (todas superiores a 50\%). Assim, para elevar ainda mais esse valor, é necessário investir em uma análise mais profunda, que incluiria análise pré, durante e pós-implantação do WMS, evitando, dessa forma, o abandono da TI, o retorno negativo ou insuficiente consequente do seu uso.

O método proposto nesse trabalho é importante, tanto para a comunidade acadêmica, quanto para as empresas. O primeiro aspecto é verificado na possibilidade de conhecimento de diferentes TIs e da forma de avaliação, quando se considera a aplicação do método para Tls além do WMS. Para as empresas, tem-se a oportunidade de utilização de um método de avaliação de TIs gratuito e amplo, abrangendo três grandes grupos de variáveis: organizacionais, de segurança e técnicas.

Esse trabalho teve como limitações um retorno reduzido das empresas para as quais os questionários foram enviados, mas teve como vantagem a participação de empresas atuantes no mercado nacional com experiência nas atividades de terceirização. Ressalta-se que tais limitações não influenciaram de forma significativa os resultados, já que as respostas dos OLs da amostra foram suficientes para o alcance do objetivo do artigo.

Pode-se sugerir como pesquisas futuras novas adaptações do método a novas TIs e a aplicação a outros setores que utilizem mais de uma TI, desde que sigam a mesma direção do método de Ribeiro (2009) e desse aqui apresentado, cortando e adicionando variáveis, adequadas à TI que o método for avaliar. A pesquisa tem originado algumas publicações, o que retrata sua aceitação pela comunidade acadêmica. Na prática empresarial, ela pode auxiliar na avaliação pelas empresas de suas Tls, para que os gerentes de TI, de logística e a alta administração reflitam quais TIs são adequadas ao negócio (considerando os aspectos aqui apresentados) e quando implantá-las.

\section{REFERÊNCIAS}

AGARWAL, R.; PRASAD, J. The role of innovation characteristics and perceived voluntariness in the acceptance of Information Technologies. Decision Sciences, v. 28, n. 3, p. 557-582, 1997. http://dx.doi.org/10.1111/j.1540-5915.1997.tb01322.x

AIGNER, M.; FELDHOFER, M. Secure symmetric authentication for RFID tags. In: Telecommunications and Mobile Computing - TCMC2005, Graz, 
Austria. Proceedings..., Áustria: Graz University of Technology, 8-9 de Março, 2005, p.1-4.

ALBERTIN, A. L.; ALBERTIN, R. M. de M. Benefícios do uso de tecnologia de informação para o desempenho empresarial. Revista de Administração Pública, RAP, v. 42, n. 2, p. 275-302, mar/abr, 2008. http://dx.doi.org/10.1590/S0034-76122008000200004

ALTER, S. Information Systems: a management perspective. 2. ed. EUA: Addison-Wesley Publishing Co. Massachusetts, 1996.

BAILEY, J. E.; PEARSON, S. W. Development of a tool for measuring and analyzing computer user satisfaction. Management Science, v. 29, n. 5, p. 530-545, May, 1983. http://dx.doi.org/10.1287/mnsc.29.5.530

BANZATO, E. Sistemas de controle e gerenciamento do armazém (WMS). Artigos de Logística. 2010.2 Disponível em: http://www.portaldomarketing.com.br. Acesso em: dez 2012.

BARROS, M. C. Warehouse management system (WMS): conceitos teóricos e implementação em um centro de distribuição. Dissertação Departamento de Engenharia Industrial, PUC-Rio, Rio de Janeiro, 2005. Disponível em: http://www.nexo.ind.puc-rio.br. Acesso em: 22 ago. 2010.

RIBEIRO, P. C. C. Proposição de um método de avaliação de Tecnologia de Identificação: o caso RFID nas cadeias de carne bovina no Brasil e nos EUA. Tese - Departamento de Engenharia de Produção, Universidade Federal de São Carlos, São Carlos, 2009.

BEYNON-DAVIES, P.; OWENS, I.; WILLIAMS, M. D. Information systems evaluation and the information systems development process. Journal of Enterprise Information Management, v. 17; n. 4, p. 276-282, 2004. http://dx.doi.org/10.1108/17410390410548689

BOYNTON, A. C.; ZMUD, R. W.; JACOBS, G. C.. The influence of IT management practice on IT use in large organizations. MIS Quarterly, v. 18, n. 3, p. 299-318, Sep. 1994. http://dx.doi.org/10.2307/249620

BRYMAN, A. Quantity and quality in social research. In: BULMER, M. (Ed). Research Methods and Organisation Studies. Routledge, London: Unwin Hyman, p. 135-169, 1989. http://dx.doi.org/10.4324/9780203359648_ chapter_5

CARVALHO, N. L. A. de. Avaliação do WMS em operadores logísticos: aplicação do método de Ribeiro e Carvalho (2011) em estudos de casos. 2012. Monografia - Departamento de Engenharia de Produção, Universidade Federal de Ouro Preto, Ouro Preto, 2012.

CHERMONT, G. S. A qualidade na gestão de projetos de Sistemas de Informação. Tese - Departamento de Engenharia de Produção, Universidade Federal do Rio de Janeiro, Rio de Janeiro, 2001.

CLEMONS, E. K. Evaluation of strategic investments in information technology. Communications of the ACM, v. 34, n. 1, p. 22-36, Jan., 1991. http://dx.doi.org/10.1145/99977.99985

(2) Revista Eletrônica de Sistemas de Informação, v. 12, n. 3, set-dez 2013, artigo 3 
DELONE, W. H.; MCLEAN, E. R. The DeLone and McLean model of information systems success: a ten-year update. Journal of Management Information System. v. 19, n. 4, p. 9-30, Mar/Jun, 2003.

DELONE, W. H.; MCLEAN, E. R. Information systems success revisited. In: Hawaii International Conference on System Sciences (HICSS - 35'02), 35., Big Island, Hawaii, Proceedings..., Big Island, Hawaii, 7-10 January 2002.

DELONE, W. H.; MCLEAN, E. R. Information systems success: the quest for the dependent variable. Information Systems Research, v. 3, n. 1, p. 6095, mar., 1992. http://dx.doi.org/10.1287/isre.3.1.60

DEPARTMENT OF TRADE AND INDUSTRY. Information Technology Security Evaluation Criteria (ITSEC). London: Department of Trade and Industry, 164p, Jun. 1991.

DIAS, R. Métricas para avaliação de sistemas de informação. Revista Eletrônica de Sistemas de Informação, v. 1, n. 1, p. 1-13, 2009. Disponível em: http://revistas.facecla.com.br. Acesso em: dez 2012.

GALVÃO JÚNIOR, M. e LIMA, S. M. Segurança e confiabilidade em Sistemas de Informação: dois lados da mesma moeda. Revista Eletrônica da Faculdade Adventista de Administração do Nordeste - FAAD, p.115- 122, 2010.

LAURINDO, F. J. B. Tecnologia da Informação: planejamento e gestão de estratégias. São Paulo: Atlas, 2008.

LEITE, J. C. S. P. Qualidade em sistemas de informação.: dividindo conhecimento sobre o uso de Tecnologias de Informação nas organizações, 2007. Disponível em: http://sisdinf.blogspot.com. Acesso em: 13/02/2011.

LEWIS, B. R.; SNYDER, C. A.; RAINIER J, R. K. An empirical assessment of the Information Resource Management Construct. Journal of Management Information Systems, v. 12, n. 1., p. 199-223, Jul.-Sep., 1995.

LIMA, Evandro. Estruturas e sistemas de informação. Universidade Paulista, 2010. Disponível em: http://www.scribd.com. Acesso em: 21 jan. 2011.

MACEDO, M. A. da Silva; BENGIO, M. da Costa._Avaliação de eficiência organizacional através de análise envoltória de dados. Congreso Internacional de Costos, 8, Uruguay, Punta del Este, Uruguay, 26-28 nov., 2003. Anais do VIII Congreso Internacional de Costos, 2010.

MAFFEZOLLI, E. C. F.; BOEHS, C. G. E. Uma reflexão sobre o estudo de caso como método de pesquisa. Revista $F A E$, v. 11, n. 1, p. 95-110, jan./jun. 2008.

MOORE, G. C.; BENBASAT, I. Development of an instrument to measure the perceptions of adopting an information technology innovation. Information Systems Research, v. 2, n. 3, p. 193-222, Sep., 1991. http://dx.doi.org/10.1287/isre.2.3.192 
OBERHOFER, C. A. Conceitos e princípios para avaliação de sistemas de informação. Ciência da Informação, v. 12, n. 1, p. 45-51, 1983.

PETTER, S.; MCLEAN, E. A meta-analytic assessment of the DeLone and McLean IS success model: an examination of IS success at the individual level, Information \& Management, v. 46, n. 3, p. 159-166, abr., 2009. http://dx.doi.org/10.1016/j.im.2008.12.006

RIBEIRO, P. C. C.; MEYER, N. R. M.; FREITAS, R. I. M. Armazenagem em operadores logísticos: uso de equipamentos e tecnologias de informação In: Encontro Nacional de Engenharia de Produção, 32., Bento Gonçalves. Anais..., 2012. v. 1, p. 1-12.

RIBEIRO, P. C. C. Proposição de um método de avaliação de Tecnologia de Identificação: o caso RFID nas cadeias de carne bovina no Brasil e nos EUA. Tese - Departamento de Engenharia de Produção, Universidade Federal de São Carlos, São Carlos, 2009.

RIBEIRO, P. C. C.; CARVALHO, N. L. A. de. Avaliação de tecnologia de informação: a ferramenta WMS e a logística. In: Simpósio de Engenharia de Produção, 18., Bauru. Anais.., 2011. Disponível em: http://www.simpep.feb.unesp.br/anais_simpep.php?e=6. Acesso em: dez 2012.

ROGERS, E.M. Diffusion of innovations. 4. ed., New York: The Free Press, 1995.

ROSA, B. Políticas de segurança em TI. Artigonal, 2010. Disponível em: http://www.artigonal.com. Acesso em: dez 2012.

SABHERWAL, R.; JEYARAJ, A.; CHOWA, C. Information System Success: individual and organizational determinants. Management Science, v. 52, n. 2, p. 1849-1864, 2006. http://dx.doi.org/10.1287/mnsc.1060.0583

SEDERA, D.; GABLE, G. A factor and structural equation analysis of the enterprise systems success measurement model. In: $25^{\text {th }}$ International Conference on Information Systems, . Proceedings of the Twenty-Fifth International Conference on Information Systems, p. 449-464, 2004.

SONNENWALD, D. H.; MAGLAUGHLIN, K .L.; WHITTON, M. C. Using innovation diffusion theory to guide collaboration technology evaluation: work in progress. In: Enabling Technologies: Infrastructure for Collaborative Enterprises (WET ICE), 10.; Cambridge, EUA. Proceedings... EUA, p. 114-119, 2001.

SOUZA, A. A. de; PASSALONGO, C. e AMARAL, H. F. Avaliação de Sistemas de Informações financeiras: estudo de casos múltiplos. Colóquio do Instituto Franco Brasileiro de Administração de Empresas, 3, 2005, Grenoble. Anais do III Colóquio do IFBAE. Grenoble : IFBAE, 2005.

SRINIVASAN, A. Alternative measures of system effectiveness: associations and implications. MIS Quarterly, v. 9, n. 3, p. 243-253, Sep. 1985. http://dx.doi.org/10.2307/248951 
STONEBURNER, G.; GOGUEN, A.; FERINGA, A. Risk management guide for information technology systems: recommendations of the National Institute of Standards and Technology. NIST Special Publication 800-30, July, 2002.

TALLON, P. P.; KAUFMANN, R. J.; LUCAS, H. C.; WHISTON, A. B.; ZHU, K. Using real option analysis for evaluating uncertain investments in information technology: insights from the ICIS 2001 debate. Communications of the Association for Information Systems, v. 9, p. 13616, 2000.

TURBAN, E.; RAINER JÚNIOR, R.K; POTTER, R. E. Administração de tecnologia da informação: teoria e prática. Rio de Janeiro: Elsevier, 2005.

YIN, R. K. Estudo de caso: planejamento e métodos. $2^{a}$. ed. Porto Alegre: Bookman, 2001.

WALRAD, C.; MOSS, E. Measurement: the key to application development quality. IBM Systems Journal, v. 32, n. 3, p. 445-460, 1993. Disponível em: http://portal.acm.org. Acesso em: dez 2012.

WANG, Y. D.; FORGIONNE, G. Testing a decision-theoretic approach to the evaluation of information retrieval systems. Journal Information Science, London, v. 34, n. 6, p. 861-876, Jul., 2008. http://dx.doi.org/10.1177/ 0165551508091308

WEILL, P.; ARAL, S. Generating premium returns on your IT investments. MIT Sloan Management Review, v. 47, n. 2, Winter, 2006.

WETHERBE, J. C. Systems analysis for computer-based information systems. St. Paul, Minneapolis, EUA: West Publishing, 1979. Disponível em: http://www. portal.acm.org. Acesso em: dez 2012. 